Feng, X \& Chen, L. (2013). Development of a scaffold design model in inter-school collaboration environment: A design-based research. Journal of Educational Technology Development and Exchange, $6(2), 39-51$.

\title{
Development of a Scaffold Design Model in Inter-school Collaboration Environment: A Design-based Research
}

\author{
Xiaoying Feng \\ Beijing Normal University \\ Li Chen \\ Beijing Normal University
}

\begin{abstract}
This study examines the development of a theoretical framework for scaffold design in an inter-school collaboration environment. The research question primarily deals with how to design scaffolds for an Inter-school Collaborative Learning (ICL). Design-based research methodology was used in this study. Literature review, questionnaire survey, field survey, and interviews were used during the course of research. Forty-seven secondary schools in 25 provinces in China were selected and participated in the study. This paper reports the first circle of design-based research. Through design-based research, a scaffold design model was developed and revised. Eight key types of scaffolding for ICL were identified. Elaborated strategies and tools were summarized for implementation of these scaffolds.
\end{abstract}

Keywords: collaborative learning, inter-school collaboration, scaffolding, instructional design

Abbreviations: ICL (Inter-school Collaborative Learning)

\section{Introduction}

As an important manner for cross-culture collaboration, Inter-school Collaborative Learning (ICL) has been proved to have significant benefits for students, teachers, and schools (Atkinson, Springate, Johnson, \& Halsey, 2007). However, as one of the most complicated models of applying Information Communications Technology (ICT) in education, ICL is difficult to implement practically (Berenfield, 1996). Teachers, especially rural teachers need assistance on how to design and conduct ICL. This study aims to provide a theoretical framework for
ICL design, so as to support rural schools to conduct ICL.

In the recent decade, academics are paying great attention on scaffolding again, especially scaffolding in a digital learning environment. Research on scaffolding in different learning environments have been focused on four key questions: (1) what types of scaffolds are needed, (2) what to scaffold, (3) when to scaffold and when to fade, and (4) how to implement scaffolding (Azevedo \& Hadwin, 2005). Some researchers have put forward their own design frameworks or models of scaffolding in different learning environments 
(Dodge, 2000; Hogan \& Pressley, 1997; Kim \& Bhang, 2008; McKenzie, 1999; Pressley \& Harris, 1992). These scaffold frameworks or models try to partly answer the above four key questions of scaffold design. In this study, the authors aim to form a scaffolding model that tries to answer the four key questions.

Therefore, this study examines the development of a theoretical framework for scaffold design in an inter-school collaboration environment. The research question is how to design scaffolds for an ICL. The scaffold design model is developed following four subquestions: (1) what types of scaffolds are needed, (2) what to scaffold, (3) when to scaffold and when to fade, and (4) how to scaffold .

\section{Methods}

\subsection{Procedures \& Methods}

Design-based research methodology was used in this study. Questionnaire survey, field survey and interviews were used for data collection during the course of research. This paper introduces the first cycle of the designbased research.

Research procedures include three steps. Step 1 is the theoretical framework that consists of the draft version of Scaffolding Model of ICL developed via literature review and survey. A literature review and survey were used in this stage. Step 2 is utilization $\&$ evaluation that consists of the framework adopted to guide the practice: a large-scale ICL practice for rural schools in China. A detailed set of scaffolds, including related strategies and tools, were designed and developed for the practice. Meanwhile, both quantitative and qualitative methods were used to collect data including questionnaires, field surveys, and interviews. Step 3 is revising the framework by including suggestions proposed on how to select and design scaffolding for ICL, especially for rural schools.

Design-based research, also called 'design research' or 'educational design research,' is "a series of approaches, with the intent of producing new theories, artifacts, and practices that account for and potentially impact learning and teaching in naturalistic settings" (Barab \& Squire, 2004, p4-5). Design-based research is characterized as (Akker, Gravenmeijer, McKenney, \& Nieveen, 2006):

- Interventionist: the research aims at designing an intervention in the real world.

- Iterative: the research incorporates a cyclic approach of design, evaluation and revision.

- Process-oriented: a black box model of input-output measurement is avoided; the focus is on understanding and improving interventions.

- Utility-oriented: the merit of a design is measured, in part, by its practicality for users in real contexts.

- Theory-oriented: the design is (at least partly) based upon theoretical propositions; and field testing of the design contributes to theory building.

Design-based research can contribute to increase the relevance of research for educational policy and practice. This study aims to develop a theoretical framework to guide the scaffold design of ICL. Designbased research aims at developing empirically grounded theories through combined study of both the process of learning and the means that support that process (diSessa \& Cobb, 2004; Gravemeijer, 1994, 1998), therefore designbased research is selected as the methodology for this study. 


\subsection{Participants}

An ICL program titled 'China Traditional physical Games\& Culture’ was conducted. This ICL program was designed to be interdisciplinary and mainly covering Chinese, Information Technology Education and Physical Education. Multi-staged stratified sampling was used to select participating schools. Forty-seven secondary schools in 25 provinces in China were selected and participated in the study. Eighty-point-two percent of participating schools were rural schools with relatively low level of ICT skills, and $47.2 \%$ of participating schools were located in West of China. Participating students were mainly in Grade 7 and Grade 8, aging from 13 to 14 years old. One hundred and six teachers participated in this project to cooperate closely with the research team and to guide their students through the ICL program with the designed scaffolds.

\subsection{Data Collection}

\subsubsection{Questionnaire}

A questionnaire survey was used in the study to collect feedback from participating teachers. Teachers were asked to evaluate the effectiveness of these scaffolds and tools in supporting the ICL. A 5-point Likert scale was used to collect responses from the participants: strongly agree, agree, neutral, disagree, and strongly disagree. Six experts in this area were invited to measure the validity of the questionnaire. A total of 69 valid questionnaires were collected with a return rate of $65.1 \%$.

\subsubsection{Qualitative data}

Interviews, field surveys, and content analysis of students' forum discussions were used to collect qualitative data. Eight participating schools were field surveyed. Oneto-one interviews were made to 8 headmasters and 8 teachers in charge. Group interviews were conducted to 33 other teachers and over 100 students. Interview questions mainly include three parts: (1) how they conducted the ICL project, (2) how they evaluated the scaffolding tools provided, and (3) their difficulties and expectations.

\section{Theoretical design Framework}

\subsection{Derivation of the Design Framework}

The theoretical framework of the study, Scaffold Model for ICL, was first derived through considering the following four issues.

\section{Issue 1: what are the key reasons/conditions for effective collaborative learning?}

The effect of collaborative learning (CL) has been supported by different theoretical principles (Huang, 2003; Johnson \& Johnson, 2002; Slavin, 1995; Zhao, 2006). Based on analysis of different theories, Salvin (1992, 1995) identified four major theoretical perspectives designed to explain the achievement effects of cooperative learning: motivational perspectives, social cohesion perspectives, cognitive perspectives, and cognitive elaboration perspectives. Based on analysis of different CL scripts, Dillenbourg and Jermann (2007) defined three types of schemata: the jigsaw schema, the conflict schema, and the reciprocal schema. Through an analysis of different theories related to CL, the authors found three key reasons or conditions for effective CL: positive interdependence, peer interaction, and cognitive conflict. These matched the three schemata defined by Dillenbourg and they emphasize key factors for successful collaboration.

Positive interdependence: In the views of motivation theory, field theory, contact theory, and social interdependence theory, the key reason/condition for success of collaborative 
learning is to promote motivation. These theories emphasize the positive interdependent and indispensible relationship between group members to promote motivation such as establishing goal interdependence, resource interdependence, and so on. The schema for positive interdependence is the jigsaw schema, which emphasizes the group members as being complementary and mutually dependent.

Cognitive conflict: According to Piaget and constructivism, the key reason or condition for the success of collaborative learning is cognitive conflict. The schema for cognitive conflict is the conflict schema.

Peer interaction: In the views of Vygotsky and social culture theory, cognitive elaboration, social learning, and humanistic learning theories believe the key reason or condition for the success of collaborative learning is the reciprocal interaction between peers. The schema for peer interaction is the reciprocal schema.

\section{Issue 2: Which strategies can support these key conditions?}

The existing practices and researches in CL field have produced a handful of strategies which can support the three key conditions (Aronson, Blaney, Sikes, Stephan, \& Snapp, 1978; Berger et al, 2001; Dillenbourg, 1999; Hermann, Rummel, \& Spada, 2001; Hoppe \& Ploetzner, 1999; Jermann \& Dillenbourg, 1999; Johnson \& Johnson, 1994; Lampe, Rooze, \& Tallent-Runnels, 1996; O’Donnell \& Dansereau, 1992; Palincsar \& Brown, 1984; Reiserer, Ertl, \& Mandl, 2002).

Strategies to support Positive Interdependence. Group incentives, goal interdependence, incentive interdependence and other strategies are widely used to support ositive Interdependence. An essential strategy for positive Interdependence is 'task specialization,' which aims to build up an interdependent and mutual-value relationship among group members. Task specialization is widely used in many popular CL approaches such as Jigsaw, GI, Finding Out, etc.

Strategies to support Cognitive Conflict. To arouse cognitive conflict, one strategy is to conduct a collaborative argument, and another is to intentionally put two sides of opposed views into one group. These strategies are widely used in collaborative debate, argument map, and other CL approaches.

Strategies to support Peer Interaction. There have been a lot of strategies to support Peer interaction such as collaborative script, peer feedback, peer evaluation, reciprocal teaching, and so on.

\section{Issue 3: Which types of scaffolds are needed for CL, according to existing scaffolding framework?}

Some researchers put forward their own design frameworks of scaffolding in different learning environments. Dodge's scaffold model for WebQuest (2000) and Kim and Bhang's scaffold framework for CSCA (2008) frameworks are the most typical. However, existing scaffolding frameworks mainly focus on two questions of scaffolding design: (1) what types of scaffolds are needed, and (2) what to scaffold. Dodge's scaffold model and Kim and Bhang's scaffold framework tried to answer the question 'how to implement scaffolding.' But, both of them implemented each scaffolding type by a list of tool examples that might still be difficult for rural teachers to operate.

Although no research on scaffolding for ICL was found, these scaffolding researches in traditional classroom, inquiry learning, and CSCL put forward different dimensions on scaffolding design. Therefore, the authors identified that the Scaffolding Model for ICL 
would try to answer the four key questions of scaffolding design. Moreover, on the fourth question 'how to implement scaffolding,' the authors proposed to adopt strategies to bridge each scaffolding type and supporting tools.

\section{Issue 4: Which scaffolds for ICL are especially needed by rural schools in China?}

The last question is to consider China's national condition. What are the main difficulties in practice when rural schools carry out ICL in China? What scaffolds do they need especially? A questionnaire survey was conducted in 50 rural middle schools across China, together with a field study in 3 rural schools of different regions. Five major difficulties were identified for rural schools to carry out ICL. With reference to the results, scaffolding needs were proposed to solve these difficulties.

The first major difficulty is low level of schools' information technology infrastructure. Information technology is required to support scaffolding. This is true in the process of ICL by which students need to know how to collect and process data and how to present their works. The second major difficulty is teachers and students' lack of experiences and abilities on collaborative learning. Hence, scaffolding support with collaboration skills is required. The third major difficulty is the heavy workload in schools, and thus, objective scaffolding is needed to provide clear objectives for schools. Content scaffolding and evaluation scaffolding are also needed to keep students on task. The forth major difficulty is the great differences between schools. On one hand, this is an actual difficulty that ICL faces. On the other hand, it is an important condition and characteristic that ICL needs to achieve its potential effects. Therefore, specific grouping scaffolding can make use of this and solve the difficulty. The fifth major difficulty is deficient emphasis of school leaders on information technology. Considering this factor, an effective incentive mechanism should be designed to stimulate school leaders' interest and enthusiasm in ICL.

\subsection{Scaffolding Framework for ICL}

Through considering comprehensively the above four issues, eight types of scaffolding for ICL are identified as shown in Table 1.

Table 1. Draft version of Scaffolding framework for ICL.

\begin{tabular}{ll}
\hline Scaffolding Type & Scaffolding Content \\
\hline Goal Orientation & Clarifies subject, purpose, and expectation of task \\
Scaffold & Provides clear direction and explains structure and content \\
Content Direction & arrangement in details \\
Scaffold & Helps in forming groups, making collaborative plans, \\
Group Building & assigning tasks, and the like. \\
Scaffold & Fosters collaborative and communication skills \\
Peer Interaction & Guides students to collect, organize, and record relevant \\
Scaffold & resources \\
Data Collection & Assists students to process and analyze collected data using \\
Scaffold & text, tables, figures, and so on. \\
Data Process Scaffold & Helps students to produce and present their project outcomes \\
Outcome Scaffold & Clarifies evaluation standards and incentive mechanism, and \\
Evaluation \& Incentive & helps assess the process and production of group collaboration \\
Scaffold & \\
\hline
\end{tabular}




\section{Results}

\subsection{Implementation}

In the cross-regional inter-school collaboration, 47 schools participated and the expected collaboration outcome was a website of 'China Traditional Physical Games $\&$ Culture.' To support the practice, 8 types of scaffolding were designed and implemented, with 24 strategies and 49 tools. Take 'Goal Orienting Scaffold' as an example, two strategies was used to scaffold students being goal-oriented: interpreting common goals and seeking unity of conceptual understanding. Three activities were designed to realize the strategy of interpreting common goals, with support of three tools. Two activities were designed to realize the latter strategy, with support of another three tools. Table 2 shows the relationship between the strategies and types of activities and tools.

Figure 1 shows a concrete example of the e-portfolio implemented for Evaluation Scaffold in this study.

The authors mainly examined whether and how effectively these 8 types of scaffolds support the ICL practice. Qualitative and quantitative data were collected to evaluate the eight types of scaffolds. A questionnaire survey was used to collect evaluation from teachers. A 5-point Likert scale was used in five levels:

Table 2. Implementation of Goal Orienting Scaffold

\begin{tabular}{lll}
\hline Strategies Used & Activities & Supporting Tools \\
\hline $\begin{array}{l}\text { Interpreting } \\
\text { common goals }\end{array}$ & $\begin{array}{l}\text { To read project introduction } \\
\text { To guide stage goals } \\
\text { To present tasks and goals of } \\
\text { big steps }\end{array}$ & $\begin{array}{l}\text { Project introduction } \\
\text { Stage goal introduction } \\
\text { Big-step task and goal } \\
\text { description }\end{array}$ \\
$\begin{array}{l}\text { Seeking unity } \\
\text { of conceptual } \\
\text { understanding }\end{array}$ & $\begin{array}{l}\text { To explain key concepts } \\
\text { To mind-storm }\end{array}$ & $\begin{array}{l}\text { Key concepts explanation, Key } \\
\text { concept illustration } \\
\text { Mind-storming introduction }\end{array}$ \\
\hline
\end{tabular}

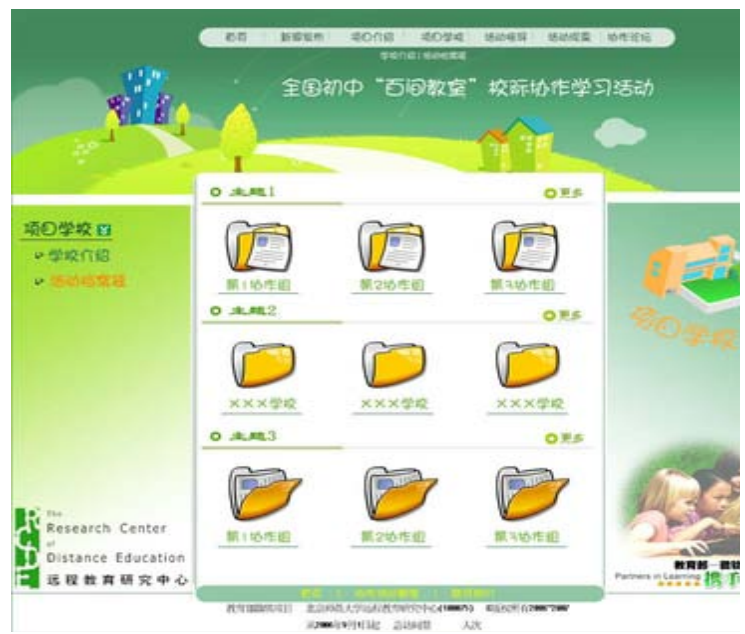

Figure 1. E-portfolio for evaluation Scaffold. 
strongly agree, agree, neutral, disagree, and strongly disagree. The authors also site-visited 8 schools, interviewed over 40 teachers and students, and observed and analyzed the postings and reflections that teachers and students created through the process.

\subsection{Findings}

Results indicated that the 8 types of scaffolds were all considered effective to support ICL, means of which varied from 4.14 4.66 (as shown in Table 3). The 25 scaffolding strategies were also considered effective, with means ranging from 4.08 4.84 and a standard error from $0.37 \sim 0.81$.

Survey results indicate that the 25 strategies and 8 types of scaffolds were regarded as very useful and supportive for ICL. Qualitative data through interviews and field surveys also show that teachers highly appraised the effectiveness of the 8 types of scaffolds on supporting them to conduct the ICL successfully. Using 'Goal Orienting Scaffold' as an example, questionnaire results showed (as in Table 4) that $94.20 \%$ and
$94.93 \%$ of teachers and students regarded its two strategies effective. Means of the two strategies were 4.507 and 4.514 .

In interviews, teachers also expressed the supportiveness of the two strategies. For instance, once teacher stated that, "In the beginning, we were confused about what is 'Sports game' and 'Sports culture'. Everyone had his own understanding. But this strategy (Seeking unity of conceptual understanding) helped us to unify our understanding and cleared obstacles for the following collaborative tasks."

However, from these survey data, observations, and interviews, the authors discovered that:

- Scaffolding of 'Group Building' and 'Peer Interaction' were inadequate. Both teachers and students approved the value and design of the two scaffold types: group building and peer interaction. However, means of the two scaffold types were the lowest with 4.14 and 4.23. During interviews, teachers expressed that

Table 3. Survey results.

\begin{tabular}{llcc}
\hline Scaffolding Type & No. of Tools & Means & SD \\
\hline Goal Orientation Scaffold & 3 & 4.51 & 0.59 \\
Content Direction Scaffold & 2 & 4.66 & 0.63 \\
Group Building Scaffold & 10 & 4.23 & 0.89 \\
Peer Interaction Scaffold & 4 & 4.14 & 0.84 \\
Data collection Scaffold & 7 & 4.50 & 0.77 \\
Data Process Scaffold & 3 & 4.27 & 0.70 \\
Outcome Scaffold & 11 & 4.62 & 0.60 \\
Evaluation \& Incentive Scaffold & 5 & 4.46 & 0.73 \\
\hline
\end{tabular}

Table 4. Questionnaire results for Goal Orienting Scaffold.

\begin{tabular}{llll}
\hline Types of scaffolding & Strategies used & Mean & SD \\
\hline \multirow{2}{*}{ Goal Orienting Scaffold } & Interpreting common goals & 4.507 & 0.590 \\
& Seeking unity of conceptual understanding & 4.514 & 0.595 \\
\hline
\end{tabular}


they were "not clear at the detailed roles, responsibilities, and tasks among different schools in our inter-school group."

- It was difficult to distinguish between 'Data Collection' scaffold and 'Data Process' scaffold. During the course of design and implementation, the authors found that the two types of scaffolds were highly inter-dependent and sometimes shared an identical supporting tool. They found that it was also difficult for teachers and students to distinguish the two in the course of application and evaluation.

- Organizational support was significantly needed in an inter-school collaboration environment. The authors found that the performance of schools in an ICL environment had high positive correlation with the attitudes of school leaders.

\subsection{Implications}

Based on the implementation, the authors concluded that the design of scaffolding was positive and effective in an ICL environment. However, these findings encouraged further refinement to the proposed scaffold design framework.

- Scaffolding on group building and peer interaction should be stronger, especially for inter-school groups. In the beginning of inter-school groups, strategies such as establishing a common identity and making group rules are necessary for inter-school group building. More strategies and activities are also needed to scaffold inter-school peer interaction.

- Data collection scaffold and data process scaffold can be integrated into one type of 'Data scaffold.'

- One type of scaffold, organizational guarantee scaffold, should be added to the scaffold design framework, which is also a specific type of scaffold in an inter-school collaboration environment. Organizational guarantee scaffold will provide both policy support and organizational support for ICL.

\section{Discussion}

\subsection{Revise of Scaffold Design Model}

Through the circle of design-based research, the scaffold design framework was revised (as shown in table 5). The 8 key types of scaffold were changed and typical strategies to implement the 8 scaffold types were confirmed.

The revised version of Scaffold Design Model for ICL tries to answer the four key questions of scaffold design in an Inter-school Collaborative Learning (ICL) environment.

\section{Question 1: What types of scaffolds are needed for ICL?}

Through the first round of design-based research, eight key types of scaffolds for ICL were re-identified, which are: target scaffold, content scaffold, group scaffold, interaction scaffold, data scaffold, outcome scaffold, evaluation scaffold, and organizational scaffold. Among them, organizational scaffold is a specific type of scaffold needed especially for inter-school collaborative learning environment.

\section{Question 2: What to scaffold?}

Scaffolding target and content of each type of scaffold was listed. For example, the 'Data Scaffold' scaffolds required students to collect, organize, and record relevant resources to process and analyze collected data using text, tables, figures, and so on. The 'Organizational Scaffold' aimed to provide both policy support and organizational support for ICL. 
Table 5. Revised version of Scaffold design framework for ICL

\begin{tabular}{|c|c|c|c|}
\hline Scaffold Type & $\begin{array}{l}\text { What to } \\
\text { scaffold }\end{array}$ & When to scaffold & How to scaffold \\
\hline Goal scaffold & $\begin{array}{l}\text { Goal } \\
\text { orientation }\end{array}$ & $\begin{array}{l}\text { Beginning of } \\
\text { each stage }\end{array}$ & $\begin{array}{l}\text { - Interpreting common goals } \\
\text { - Seeking unity of conceptual } \\
\text { understanding }\end{array}$ \\
\hline $\begin{array}{l}\text { Content } \\
\text { scaffold }\end{array}$ & $\begin{array}{l}\text { Content } \\
\text { direction }\end{array}$ & $\begin{array}{l}\text { The whole } \\
\text { process }\end{array}$ & $\begin{array}{l}\text { - Structured presenting activity content } \\
\text { - Offering clear schedule } \\
\text { - Guiding by different roles }\end{array}$ \\
\hline Group scaffold & Group building & $\begin{array}{l}\text { Initial stage of } \\
\text { each group }\end{array}$ & $\begin{array}{l}\text { - Forming a group } \\
\text { - Ice-breaking } \\
\text { - Establishing common identity } \\
\text { - Making common rules } \\
\text { - Making clear responsibilities }\end{array}$ \\
\hline $\begin{array}{l}\text { Interaction } \\
\text { scaffold }\end{array}$ & $\begin{array}{l}\text { Peer } \\
\text { interaction }\end{array}$ & $\begin{array}{l}\text { The whole } \\
\text { interaction } \\
\text { process }\end{array}$ & $\begin{array}{l}\text { - Explanation } \\
\text { - Argument } \\
\text { - Raising questions } \\
\text { - Problem solving } \\
\text { - Sharing and communication }\end{array}$ \\
\hline Data scaffold & $\begin{array}{l}\text { Data collection } \\
\& \text { data process }\end{array}$ & $\begin{array}{l}\text { Problem-solving } \\
\text { process }\end{array}$ & $\begin{array}{l}\text { - Preparing for methods } \\
\text { - Making plans } \\
\text { - Process recording } \\
\text { - Data analysis } \\
\text { - Multimedia processing }\end{array}$ \\
\hline $\begin{array}{l}\text { Outcome } \\
\text { Scaffold }\end{array}$ & $\begin{array}{l}\text { Design, } \\
\text { production, \& } \\
\text { distribution of } \\
\text { group works }\end{array}$ & $\begin{array}{l}\text { The forming } \\
\text { process of group } \\
\text { works }\end{array}$ & $\begin{array}{l}\text { - Designing of works } \\
\text { - Producing and distributing }\end{array}$ \\
\hline $\begin{array}{l}\text { Evaluation } \\
\text { Scaffold }\end{array}$ & $\begin{array}{l}\text { Evaluation \& } \\
\text { motivation }\end{array}$ & $\begin{array}{l}\text { at the beginning } \\
\& \text { end }\end{array}$ & $\begin{array}{l}\text { - Making clear evaluation standards } \\
\text { - Reflection } \\
\text { - Establishing reward systems } \\
\text { - e-portfolio }\end{array}$ \\
\hline $\begin{array}{l}\text { Organizational } \\
\text { Scaffold }\end{array}$ & $\begin{array}{l}\text { Policy and } \\
\text { organizational } \\
\text { guarantee }\end{array}$ & $\begin{array}{l}\text { The whole } \\
\text { process, but } \\
\text { especially at the } \\
\text { early beginning }\end{array}$ & $\begin{array}{l}\text { - Forming unions of school principals } \\
\text { - Optimizing the organizational } \\
\text { structure } \\
\text { - Seeking policy suppor }\end{array}$ \\
\hline
\end{tabular}




\section{Question 3: When to scaffold/when to fade?}

The revised version of Scaffold Design Model for ICL analyzed when each type of scaffold was needed and when to fade. For example, the 'Organizational Scaffold' is needed all throughout the process of ICL, and especially necessary at the beginning of ICL. Important was to provide clear and sufficient policy support at the early beginning of ICL, so as to guarantee the incentive and engagement of teachers and students.

\section{Question 4: How to implement scaffolding?}

In this model, the authors suggested that each type of scaffold be implemented through some strategies, and these strategies be further supported with some tools. Typical strategies and samples of tools were summarized for each type of scaffold. For example, the 'Content Scaffold' could be implemented through 3 typical strategies: (1) presenting structured activity content, (2) offering clear schedule, and (3) guiding by different roles. To support its implementation, some supporting tools could be developed and provided such as a mind-map, a timetable, and a role-based collaboration script.

\subsection{Guidelines of Choosing and Designing Scaffolds for ICL}

With reference to the practice and results in the study, some guidelines were concluded on the selection and design of scaffolds for ICL, especially for rural schools.

a) This study indicated that eight key types of scaffolding were needed to support ICL from different dimensions.

b) As one of the most complicated collaborative learning, Inter-school Collaborative Learning is difficult not for only students, but also for teachers and school leaders. Therefore, in an Inter-school Collaborative Learning environment, scaffolds should be designed and provided for students, teachers, and school leaders.

c) Not only eight types of scaffolds should be designed for ICL, but also detailed strategies and tools should be developed to support rural schools. In this study, the authors found that scaffold design would be much easier and feasible through the three layer implementation of 'scaffold type - strategies - supporting tools.'

d) Design and development of three types of scaffolds should be emphasized: content scaffold, outcome scaffold, and goal scaffold.

e) In order to achieve an in-depth interschool collaboration, it is important to strengthen the scaffolding intensity for inter-school groups. Because school-toschool collaboration is the most difficult to achieve, the design of 'Group Scaffold' and 'Interaction Scaffold' should lay stress on scaffolding of inter-school groups.

f) Scaffolding intensity of each type should vary in accordance with different targets and stages.

\section{Conclusion}

This study aims to develop a scaffold design model to support inter-school collaboration. Through design-based research, a scaffold design model was developed and revised. Eight key types of scaffolding for ICL were identified. Elaborated strategies and tools were summarized for implementation of these scaffolds. This study and the scaffold design model are expected to provide a theoretical framework and guidelines on how to select and design scaffold in an interschool collaboration environment. 
This study's main contribution is the theoretical framework for ICL design which may not only guide the instructional design of ICL, but also be helpful for scaffold design in other learning environments. However, the limitation is that design-based research is timeconsuming, and only one circle of designbased research is examined in this study. In the future, more circles of design-based research and further experimental studies would be conducted to further refine the framework.

\section{References}

Akker, J.V., Gravenmeijer, K., McKenney, S., \& Nieveen, N. (2006). Educational Design Research. Taylor \& Francis.

Aronson, E., Blaney, N., Sikes, J., Stephan, G., \& Snapp, M. (1978). The Jigsaw Classroom. Beverly Hills, CA: Sage Publication.

Atkinson, M., Springate, I., Johnson, F., \& Halsey, K. (2007). Inter-school collaboration: a literature review. Slough: NFER.

Azevedo, R., \& Hadwin, A.F. (2005). Scaffolding self-regulated learning and metacognition - Implications for the design of computer-based scaffolds. Instructional Science, 33, 367-379

Barab, S., \& Squire, K. (2004). Design-based research: Putting a stake in the ground. Journal of the Learning Sciences, 13(1), $1-14$.

Berenfield, B. (1996). Linking students to the infosphere. Technological Horizons in Education (T.H.E. Journal), 23(9), 76-83.

Berger, A., Moretti, R., Chastonay, P., Dillenbourg, P., Bchir, A., Baddoura, R., Bengondo, C., Scherly, D., Ndumbe, P., Farah, P., \& Kayser, B. (2001). Teaching community health by exploiting international socio-culturaland economical differences. In P. Dillenbourg, A. Eurelings, \& K. Hakkarainen. Proceedings of the first European Conference on Computer Supported Collaborative Learning (pp. 97-105), Maastricht, March 2001.

Dillenbourg, P. (1999). What do you mean by collaborative learning? In P. Dillenbourg (Ed). Collaborative-learning: Cognitive and Computational Approaches (pp.1-19). Oxford: Elsevier

Dillenbourg, P., \& Jermann, P. (2007) Designing Integrative Scripts. In: Fischer, F., Kollar, I., Mandl, H., Haake, J. (eds.). Scripting Computer-Supported Collaborative Learning: Cognitive, Computational, and Educational Perspectives (pp. 277-302). New York: Springer.

diSessa, A. A., \& Cobb, P. (2004). Ontological innovation and the role of theory in design experiments. Journal of the Learning Sciences, 13(1), 77-103.

Dodge, B. (2000). Thinking visually with WebQuest. Retrieved June 9, 2006, from http://webquest.sdsu.edu/webquest.html

Gravemeijer, K. (1994). Developing Realistic Mathematics Education. Utrecht, NL: Cdß-Press.

Gravemeijer, K. (1998). Developmental research as a research method. In J. Kilpatrick \& A. Sierpinska (Eds.) Mathematics education as a research domain: A search for identity (pp. 277295). Dordrecht, NL: Kluwer Academic Publishers.

Hermann, F., Rummel, N., \& Spada, H. (2001). Solving the case together: The challenge of net-based interdisciplinary collaboration. European perspectives on computer-supported collaborative learning: Universiteit Mastricht.

Hogan K. E., \& Pressley, M E. (1997). Scaffolding student learning: Instructional approaches and issues. Cambridge: Brookline Books, Inc.

Hogan, K., \& Pressley, M. (1997). Scaffolding 
student learning: instructional approaches \& issues. Cambridge: Brookline Books, Inc Hoppe, U. H., \& Ploetzner, R. (1999). Can analytic models support learning ingroups. In P. Dillenbourg (Ed.) Collaborativelearning: Cognitive and Computational Approaches (pp.147-168). Oxford: Elsevier.

Huang, R.H. (2003). Computer-supported Collaborative Learning - Theory and Methods. Beijing: People's Education Press.

Jermann, P., \& Dillenbourg, P. (1999, December). An analysis of learner arguments in a collective learning environment. In Proceedings of the 1999 conference on computer support for collaborative learning (p. 33). International Society of the Learning Sciences.

Johnson, D.W., \& Johnson, R.T. (2002). Cooperative Learning and Social Interdependence Theory. Social Psychological Applications to Social Issues, 4, 9-35.

Johnson, R. T., \& Johnson, D.W. (1994). An Overview of Cooperative Learning. In J. Thousand, A. Villa, \& A. Nevin (Eds), Creativity and Collaborative Learning (pp.1-18). Baltimore, MD: Brookes Press.

Kim, D., \& Bhang, S. (2008, November). The Effect of Scaffolding of Critical Thinking skills for Meaningful Interaction in Collaborative Argumentation. In World Conference on E-Learning in Corporate, Government, Healthcare, and Higher Education (Vol. 2008, No. 1, pp. 17101713).

Lampe, J. R., Rooze, G. E., \& Tallent-Runnels, M. (1996). Effects of cooperative learning among Hispanic students in elementary social studies. Journal of Educational Research, 89, 187-191.

McKenzie, J. (1999). Scaffolding for success. The Educational Technology Journal, 9(4), 12.
O'Donnell, A. M., \& Dansereau, D. F. (1992). Scripted cooperation in studentdyads: A method for analyzing and enhancing academic learning andperformance. In R. Hertz-Lazarowitz \& N. Miller (Eds.), Interaction incooperative groups: The theoretical anatomy of group learning (pp. 120-141). London: Cambridge University Press.

Palincsar A.S., \& Brown A.L. (1984). Reciprocal teaching of comprehensionfostering and comprehension-monitoring activities. Cognition and Instruction, 1(20), 117-175.

Pressley, M., Harris, K. R., \& Marks, M. B. (1992). But good strategy instructors are constructivists!. Educational Psychology Review, 4(1), 3-31.

Reiserer, M., Ertl, B., \& Mandl, H. (2002). Fostering Collaborative Knowledge Construction in Desktop Video conferencing. Effects of Content Schemesand Cooperation Scripts in PeerTeaching Settings. In G. Stahl (Ed.), Computer support for collaborative learning: foundations for a CSCL community (pp. 379-388). Mahwah, NJ: Lawrence Erlbaum Associates.

Slavin, R.E. (1992). When and why does cooperative learning increase achievement? Theoretical and empirical perspectives. In R. Hertz-Lazarowitz \& N. Miller (Eds.), Interaction in cooperative groups: The theoretical anatomy of group learning (pp.145-173). New York: Cambridge University Press

Slavin, R.E. (1995). Cooperative learning: Theory, research, and practice (2nd Ed.). Boston, MA: Allyn \& Bacon.

Zhao, J.H. (2006). Computer-supported Collaborative Learning. Shanghai: Shanghai Education Press. 
Development of a Scaffold Design Model in Inter-school Collaboration Environment:

A Design-based Research

\section{Contact the Authors}

\section{Xiaoying Feng}

Beijing Normal University

Email: eaglet@bnu.edu.cn

\section{Li Chen}

Beijing Normal University

Email: lchen@bnu.edu.cn 